\author{
RAIANNY PIRES LÔBO \\ KARINA SOARES CORRÊA \\ RODRIGO DE ARAÚJO BERTO
}

ESTUDOS DE EFICIÊNCIA DOS HORMÔNIOS HIPOFISÁRIOS DE ORIGEM EQUINA EM RATOS 


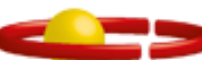 \\ Unce=UB \\ Centro Unıversıtárı de Brasílı \\ RAIANNY PIRES LÔBO \\ KARINA SOARES CORREAA \\ RODRIGO DE ARAÚJO BERTO
}

\section{ESTUDOS DE EFICIÊNCIA DOS HORMÔNIOS HIPOFISÁRIOS DE ORIGEM EQUINA EM RATOS}

\author{
Relatório final de pesquisa de Iniciação Científica \\ apresentado à Assessoria de Pós-Graduação e \\ Pesquisa pela Faculdade de Ciências da \\ Educação e da Saúde - FACES. \\ Orientação: Daniela Oliveira Brandão
}




\title{
ESTUDO DA EFICIÊNCIA DOS HORMÔNIOS HIPOFISÁRIOS DE ORIGEM EQUINA EM RATOS
}

\author{
Raianny Pires Lôbo - UniCEUB, PIBIC-CNPq, aluno bolsista \\ raiplobo@gmail.com \\ Karina Soares Corrêa- UniCEUB, colaborador \\ karinasoares1298@gmail.com \\ Rodrigo de Araújo Berto- UniCEUB, colaborador \\ rodrigo01berto@hotmail.com
}

Adalberto Farinasso - médico veterinário, pesquisador Msc. colaborador mvafarinasso@gmail.com

Carlos Alberto Da Cruz Júnior- UniCEUB, pesquisador Dr. colaborador

carlos.junior@uniceub.br

\section{Daniela Oliveira Brandão - UniCEUB, professor orientador}

daniela.brandao@uniceub.br

Com bioeficiência comprovada em equinos, foi realizado no UniceubLABOCIEN o primeiro estudo em Rattus novergicus (linhagem Wistar) utilizando gonadotrofina (hormônio LH:FSH) e somatotrofina (hormônio do crescimento ou GH) extraídos de hipófises equinas coletadas em abatedouro. Para testar a gonadotrofina equina, 35 fêmeas pré-púberes com peso vivo médio de $54,5 \mathrm{~g}$ foram divididas nos tratamentos Placebo, $0,025 \mathrm{UI}, 1 \mathrm{UI}$ ou $10 \mathrm{UI}$ de gonadotrofina equina, e $10 U \mathrm{l}$ de eCG (Novormon®), por dose, por 3 dias consecutivos, via subcutânea. Todos os tratamentos foram associados com 4Ul/dia de hCG conforme protocolo da farmacopeia internacional. Já a somatotrofina foi testada com 28 machos prépúberes com peso vivo médio de $50,7 \mathrm{~g}$ nos tratamentos Placebo, 0,025UI, $1 \mathrm{UI}$ ou $10 \mathrm{UI}$ de somatotrofina equina por dose via subcutânea, 3 dias/semana, durante 30 dias. Os animais foram mantidos em gaiolas individuais em estantes ventiladas, com ciclo de $12 \mathrm{~h}$ escuro e $12 \mathrm{~h}$ claro, água e ração ad libitum. Ambos os hormônios tiveram delineamento inteiramente casualizado com 7 repetições, sendo as médias resultantes comparadas pelo teste de Tukey $(p<0,01)$. Ao final do experimento os animais foram eutanasiados, pesados e necropsiados. O peso médio relativo dos ovários das fêmeas Placebo $(0,46 \mathrm{~g})$ não diferiu das doses $0,025 \mathrm{UI}(0,63 \mathrm{~g})$ ou $1 \mathrm{UI}$ $(0,63 \mathrm{~g})$. As médias nos tratamentos $10 \mathrm{UI}$ de gonadotrofina equina $(1,01 \mathrm{~g})$ e $10 \mathrm{UI}$ do produto comercial eCG $(0,83 \mathrm{~g})$ foram as mais elevadas, mas não diferiram entre si. Não houve diferença entre as médias de peso corporal final $(54,5 \mathrm{~g})$ e médias de ganho de peso relativo $(29,0 \mathrm{~g})$. Nos machos foram pesados fígado, rins, coração e baço, bem como o aparelho reprodutor intacto (excluindo pênis) para avaliação macroscópica. Não houve diferença entre as médias de peso corporal final $(50,7 \mathrm{~g})$, comprimento $(35,8 \mathrm{~cm})$, ou peso médio relativo dos órgãos fundamentais, bem como seu aspecto. Já o aparelho reprodutor dos machos tratados apresentou modificação macroscópica no padrão de irrigação sanguínea, com maior ramificação e espessamento aparente nos vasos dos testículos, epidídimo, ducto deferente, vesícula seminal e plexo pampiniforme. Houve também aparente incremento de gordura justaposta aos órgãos fundamentais e plexo pampiniforme. Nenhum grupo tratado apresentou reação tecidual, alteração dos órgãos ou efeitos colaterais aparentes, indicando assim inocuidade das moléculas. Todos os órgãos avaliados em todos os tratamentos foram fixados em formaldeído $10 \%$ para análise 
microscópica. Os resultados avaliados confirmaram a atividade das gonadotrofinas equinas, com incremento de peso ovariano em fêmeas pré-púberes. $\mathrm{O} G \mathrm{GH}$ equino apresentou indicadores de suas atividades angiogênica e metabólica, devendo ser estudado em tratamentos mais prolongados. Sendo o equino doador universal de hormônio proteico, incluindo para humanos, o trabalho indica a bioatividade dos hormônios hipofisários de origem equina também nos ratos, espécie heteróloga fundamental nos estudos científicos.

Palavras-Chave: Fisiologia. Biotecnologia. Metabolismo. Reprodução. Hipófise. 


\section{Agradecimentos}

Agradeço a todos que fizeram parte do desenvolvimento e elaboração desse trabalho, e que contribuíram direta ou indiretamente para que ele fosse realizado.

Agradeço especialmente à Professora Daniela Oliveira Brandão, que me orientou durante todo o projeto, transmitindo conhecimentos e instruindo, abriu meus olhos para novas possibilidades na área da Medicina Veterinária.

Ao Coordenador Carlos Alberto da Cruz Júnior, pelo comprometimento e dedicação a esse projeto.

A todos os meus colegas que dedicaram seu tempo a esse trabalho, em especial à Karina Soares Corrêa e Rodrigo de Araújo Berto, que desde o início dos experimentos se mostraram comprometidos, sempre me auxiliando e dando apoio. $\mathrm{E}$ também ao José Maria Cavalcante Andrade e Daniel Felipe Cherchi Silva, por toda a dedicação e disposição para ajudar.

Ao Programa de assessoria de Pós-Graduação e Pesquisa do UniCEUB, que sempre se mostraram disponíveis e deram todo o apoio necessário. Ao CNPq, pela bolsa que permitiu a elaboração do projeto.

Agradeço também toda a equipe do LABOCIEN-UNICEUB, que nos cedeu o espaço para a realização dos experimentos e sempre nos auxiliou e deu apoio, especialmente o Nilo, que nos direcionou e auxiliou nas atividades no biotério e sempre se mostrou apto a ajudar. 


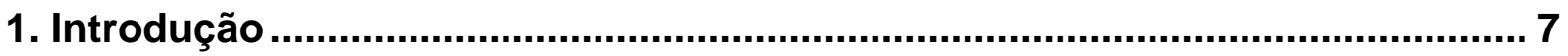

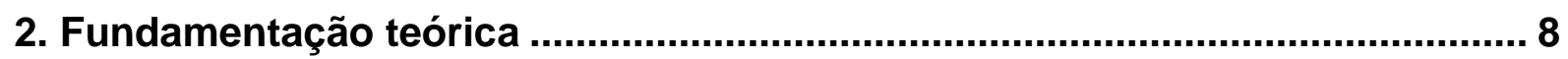

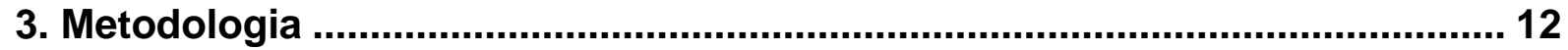

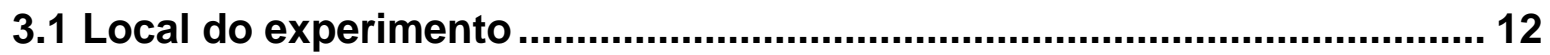

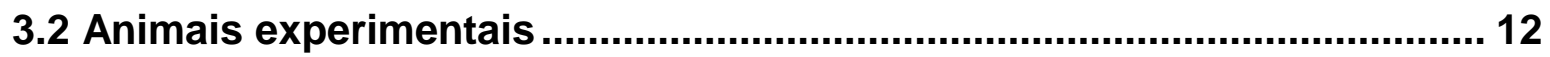

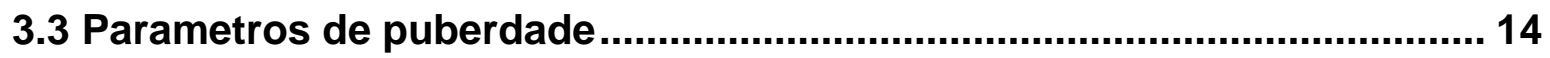

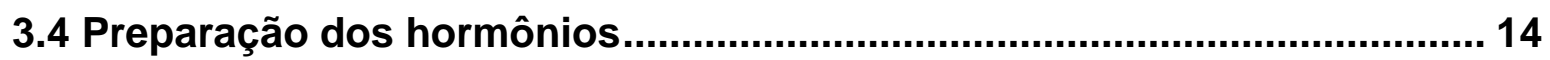

3.5 Protocolos de tratamento hormonal ......................................................... 14

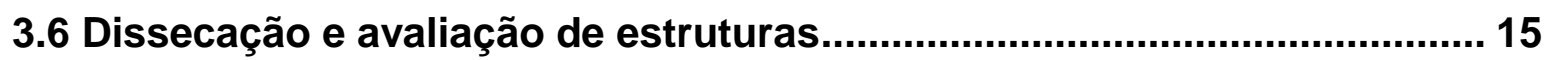

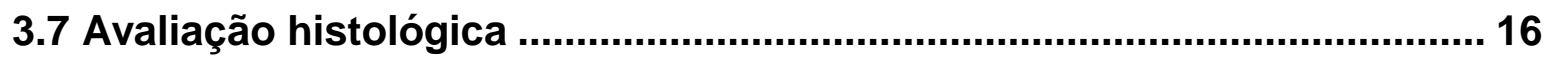

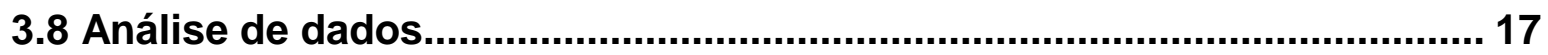

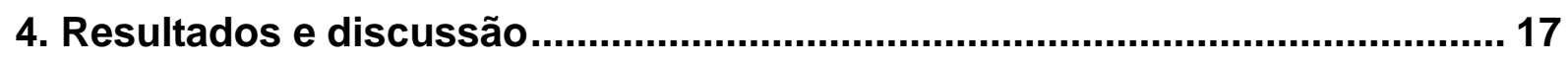

Tabela 1 - Avaliação de dose-resposta ovariana para $\mathrm{FSH}^{\star}$ em fêmeas Rattus novergicus (Linhagem Wistar heterozigotas) pré-púberes induzidas com gonadotrofina hipofisária equina em três diferentes concentrações e gonadotrofina coriônica equina (eCG) de uso comercial (10Ul/dia). ${ }^{* *}$............Erro! Indicador não definido.

Tabela 2 - Avaliação histológica de ovários de fêmeas Rattus novergicus (Linhagem Wistar heterozigotas) pré-púberes induzidas com gonadotrofina hipofisária equina em três diferentes concentrações e gonadotrofina coriônica equina (eCG) de uso comercial (10Ul/dia)................ Erro! Indicador não definido.

Figura 1 - Imagem fotográfica do aparelho reprodutor de fêmeas Rattus novergicus grupo Placebo (A), 0,025UI (B), 1UI (C) ou 10UI (D) de gonadotrofina equina, e 10UI de eCG (E). Erro! Indicador não definido.

Tabela 3 - Medidas corporais e de órgãos fundamentais ( $\mathrm{g}$ ) de machos Rattus novergicus (Linhagem Wistar heterozigotos) pré- púberes tratados por 30dias* com somatotrofina hipofisária equina em três diferentes concentrações.......Erro! Indicador não definido.

Figura 2 - Imagem fotografica do aparelho reprodutor de machos Rattus novergicus grupo Placebo (A), 0,025UI (B), $1 \mathrm{UI}$ (C) ou $10 \mathrm{UI}$ (D) de somatotrofina hipofisária equina............................. Erro! Indicador não definido.

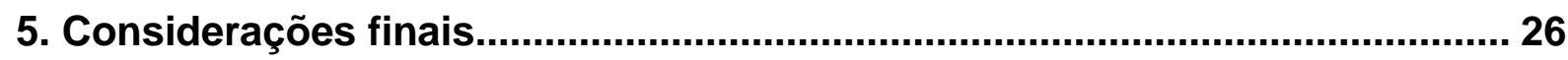

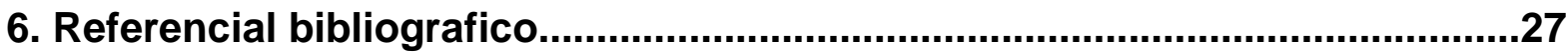




\section{Introdução}

Os primeiros estudos utilizando hipófises equinas como fonte de gonadotrofinas contavam com um extrato bastante bruto, sendo denominado de forma geral de Extrato de Pituitária Equina ou EPE (FARIA e GRADELA, 2010). Segundo Palmer (1993), embora o EPE não induza a formação de anticorpos como a hCG, a heterogeneidade das amostras disponíveis deveria ser considerada um problema. Já os extratos purificados na nova tecnologia apresentavam mais elevado grau de purificação, sendo um enorme avanço diante dos produtos prévios (FARINASSO, 2004).

Apesar da nova era dos recombinantes, todo o mercado animal é ainda dependente de extratos oriundos do sangue de éguas gestantes, o PMSG (Pregnant Mare Serum Gonadotrofin) ou eCG (Equine Chorionic Gonadotrofin), e do hCG (Human Chorionic Gonadotropin), proveniente de urina de mulheres gestantes (BARUSELLI et al., 2008). Este último, antigamente muito utilizado na reprodução assistida de equinos, tem hoje elevada rejeição pelo mercado, considerando seu custo elevado e inatividade quando ao uso repetido por 2 a 3 aplicações. Assim, a maior fonte de $\mathrm{LH} / \mathrm{FSH}$ da indústria animal continua a ser a espécie equina (LUNENFELD, 2004).

Após 12 anos de testes em equinos, uma nova tecnologia de extração a partir de hipófises equinas de abatedouro, processo patenteado em conjunto com a Universidade de Brasília, permitiu êxito na obtenção de dois produtos nobres (GH e $\mathrm{LH} / \mathrm{FSH}$ ) a partir de um mesmo material descartado da indústria animal, conferindo economia, flexibilidade e sustentabilidade futura da tecnologia. A contribuição dos mais de 2000 tratamentos realizados em 20 estados do Brasil nos últimos 10 anos permitiu o ajuste bastante refinado de dose-efeito, revelando uma relação de bioequivalência segura e estável em equinos.

Assim, o presente projeto visa avaliar em ratos as relações de dose-efeito, já que são eles os modelos animais básicos para a padronização de bioequivalência em todo o mundo, tanto para o hormônio do crescimento quanto as gonadotrofinas. 


\section{Fundamentação teórica}

\section{Histórico dos hormônios hipofisários}

Desde sua descoberta por Crowe e colaboradores em 1910, a história dos hormônios hipofisários é recheada de interações experimentais e terapêuticas entre humanos e animais. Outros 15 anos foram necessários até que Zondek (1926) observasse que os efeitos da inoculação de hipófises bovina e humana em ratos incrementava rapidamente o desenvolvimento sexual. Desde então, inúmeros experimentos tiveram os mesmos fins, confirmando a importância da glândula para diversas anormalidades já relatadas por Aschner desde 1912. Estavam assim descobertos os hormônios gonadotróficos (ASRM, 2008). Em 1948, a revista americana Life exibe orgulhosamente ratos e cães agigantados pela inoculação de proteína hipofisária realizadas pelo Dr. Evans. Era a vez do hormônio do crescimento $(\mathrm{GH})$, ou somatotrofina.

Um alerta dessa interação terapêutica entre mamíferos ocorreu, entretanto, em 1945 quando pessoas com deficiência de crescimento tratadas com extratos hipofisários de cadáveres humanos desenvolveram uma síndrome já descrita por Creutzfeldt e Jakob desde 1920. Em 1963, o FDA determinou a retirada de todos os produtos de origem humana do mercado. Somente na década de 90 na Inglaterra, com a deflagração da Encefalite Espongiforme Bovina, ou Doença da Vaca Louca, os príons ganharam exposição à sociedade daquele mal que também atingia o homem. As doenças priônicas, já descritas em pequenos ruminantes desde 1948, marcavam assim uma nova era na busca de repositores hipofisários compatíveis com a saúde. A inoculação de proteínas entre primatas e entre ruminantes era proibitiva (STANLEY, 2001; ZABEL e REID, 2015). Os equinos, espécie evolutivamente refratária aos príons, torna-se doador universal de hormônios hipofisários (LUNENFELD, 2004).

Reforçada pelos príons, tem início a frenética era da síntese de hormônios a partir da recombinação gênica de bactérias, tanto para humanos quanto animais, afim de suprir uma demanda mundial mínima por hormônios hipofisários (AYYAR, 2011). No Brasil, apesar dos esforços de desenvolvimento de recombinantes, o 
suprimento de tais produtos é ainda 100\% dependente de importação para os quais os custos e limitações de qualidade são ainda um obstáculo. A diferença entre os dois hormônios é que as enquanto os produtos somatotrópicos são absolutamente de origem recombinante, as gonadotrofinas contam ainda com os extratos de éguas ou mulheres gestantes, mesmo que já existam os biosintéticos.

\section{Gonadotrofinas na atualidade}

Segundo a relatado pela American Society for Reproduction Medicine (2008), "a terapia com gonadotrofinas é tão central para o tratamento da infertilidade que tornase fácil entender o considerável número de descobertas e pesquisas que precederam a produção de compostos mais puros e efetivos de hoje. A história subjacente de desenvolvimentos aproxima de 100 anos e fornece um esplendido exemplo a experimentação básica animal e os avanços tecnológicos progrediram aos tratamentos clínicos". Assim, tanto em animais quanto humanos, os hormônios gonadotróficos (LH/FSH) são a base das terapias de recuperação ou incremento de fertilidade, bem como manipulação do ciclo para a reprodução assistida (inseminação artificial, produção de embriões, congelamento de sêmen, cultivo celular, etc).

Doadora universal para todas as espécies, incluindo humanos, a gonadotrofina equina é extraída a partir do sangue de éguas entre 60 e 150 dias de gestação, quando sintetizam na placenta uma proteína com efeitos similares ao LH/FSH. No Brasil, o eCG é o medicamento básico das biotécnicas da reprodução em bovinos como a inseminação Artificial (IA), IA em Tempo Fixo (IATF) e múltiplas ovulações e transferência de embriões (MOET), sendo a base de protocolos hormonais de sincronização de cio e consequentemente inseminação (BARUSELLI, 2008). Somente nessa espécie, a IATF apresentou crescimento superior a $20 \%$ entre 2010/11, atingindo em 2015 patamares próximos aos 8 milhões de protocolos hormonais (ASBIA, 2015). O mesmo uso se repete em suínos e pequenos ruminantes.

Apesar de seu amplo uso, o eCG hoje produzido na Europa e América Latina (Argentina e Uruguai) tem a continuidade de sua fabricação seriamente ameaçada na sociedade moderna. No Uruguai, grande exportador de sangue e plasma equinos da América Latina, há grande movimento da sociedade contra as contínuas sangrias 
das éguas gestantes e os abortos induzidos para nova gestação e máxima exploração possível ao ano (acessar: <http://www.dw.com/es/sangr\%C3\%ADa-deyeguas-una-pr\%C3\%A1ctica-controvertida/a-18764803>). A atividade determina a morte ou envio precoce aos abatedouros pelas mazelas geradas. Há 10 anos, um grupo de pesquisadores brasileiros conseguiu com sucesso a extração de PMSG, mas nenhum produto comercial foi disponibilizado (ALEIXO et al., 1994)

\section{Somatotrofinas na atualidade}

A somatotrofina ou hormônio do crescimento $(\mathrm{GH})$ é um polipeptídeo produzido e secretado por células especializadas localizadas na hipófise anterior, e cuja principal função é a promoção do crescimento e desenvolvimento corporal; além disso, participa da regulação do metabolismo de proteínas, lipídeos e carboidratos (DAVIDSON, 1987; CASANUEVA, 1992). Devido às características de sua liberação (pulsátil e circadiana), não é possível a purificação a partir de outras fontes que não sejam a própria hipófise, e portanto, tem somente produtos de origem recombinante atualmente, diferentemente das gonadotrofinas.

O grande contingente reconhecido e mundial para o uso do $\mathrm{GH}$ recombinante (Recombinant Bovine Somatotropin - rBST) está na produção animal, e apesar de controverso, é destinado à estimulação da produção de leite bovino (FAO/WHO, 2013). No Brasil, três produtos comerciais estão disponíveis. Assim como em humanos, o hormônio é amplamente procurado para os tratamentos da deficiência de crescimento e melhora de desempenho físico, bem como adjuvante na reparação tecidual.

Já nos equinos é possível a importação do hormônio do crescimento recombinante equino ( $\mathrm{rEGH})$, mas os relatos de seu uso remetem a enorme dor, prostração, inchaço local e regional, febre e inapetência, fatores que levam à rejeição do produto por profissionais e criadores. Em artigos científicos, os efeitos colaterais são geralmente subnotificados, mas foram claramente descritos por De Botton, D; Janett, F; Burger et al. (2008), à semelhança dos problemas relatados por usuários no Brasil.

\section{Proposta da Extração Hipofisária com Nova Tecnologia}

Nesse complexo cenário, uma nova tecnologia de extração de proteínas hormonais a partir de hipófises equinas de abatedouro tem se mostrado uma valiosa 
alternativa para a obtenção tanto do LH/FSH (FARINASSO, 2004). Ao participar do programa de incubação no Centro de Desenvolvimento Tecnológico da Universidade de Brasília através da pessoa jurídica Laboratório Unicórnio Ltda., a tecnologia, ainda rudimentar, obteve seu primeiro registro de patente.

A continuidade de desenvolvimento em numerosos ensaios em equinos levou à redução substancial da dose inicialmente trabalhada, o que significava um maior grau de pureza das amostras obtidas. Além disso, o estudo e modificações do protocolo de extração permitiram a obtenção das somatotrofinas, além das gonadotrofinas já expressadas no EPE. Com isso, Itho (2010) obteve excelentes resultados na indução de múltiplas ovulações em éguas associando a somatotropina e a gonadotrofina de hipófise equina com uma dose bastante pequena em relação aos trabalhos de 2004.

Logo depois, Nogueira (2011) publicou o uso da gonadotrofina de hipófise equina como método de indução de ovulação em éguas a serem inseminadas artificialmente, obtendo mais de $90 \%$ de induções bem-sucedidas. A indução de ovulação em éguas é um enorme obstáculo para os profissionais. Segundo artigos revisados pela autora, os produtos disponíveis no mercado não garantem a ovulação em tempo preciso para a inseminação artificial, que necessita de janela terapêutica bastante reduzida. Este fato torna o uso de sêmen, principalmente quando congelado, uma técnica de complexo uso para os profissionais, diminuindo a possibilidade de intercâmbio genético nacional e internacional.

O trabalho de purificação e os ensaios executados com hipófise equina levaram à precisão das relações de dose-efeito, e hoje está estabelecido que, cada $1 \mathrm{mg}$ do extrato hipofisário, corresponde a $500 \mathrm{UI}$ (unidades internacionais), tanto para as gonadotrofinas quanto somatotrofinas. O diluidor básico é a solução fisiológica, sem qualquer adjuvante ou bacteriostático adicional. Cada hipófise processada gera 1,2 $\mathrm{mg}$ de extrato, de cada um dos hormônios. A relação $\mathrm{mg}$ e Ul encontrada nos produtos é muito distante daquela encontrada nos produtos comerciais, onde cada 1 $\mathrm{mg}$ contém entre 3 e 10Ul. Este é um dado importante, que condiz com o grau de pureza obtido.

Assim, o início dos estudos em Rattus novergicus abre um novo e potencial campo de pesquisas e inovação, em um tema importante e muito necessário à biotecnologia. 


\section{Metodologia}

\subsection{Local do experimento}

O presente estudo foi conduzido no UNICEUB da SEPN, 707/907, Via W 5 Norte

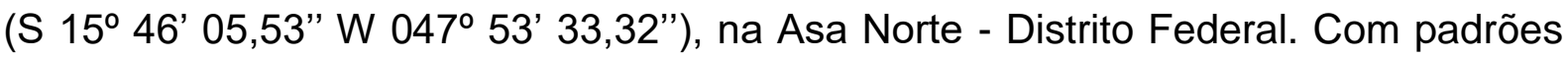
que atendem às normas internacionais de pesquisa, os experimentos foram conduzidos no LABOCIEN-UNICEUB, onde animais experimentais são mantidos em condições de clima e isolamento que geram mínimo impacto entre repetições dentro dos grupos.

A estabilidade e qualidade do LABOCIEN-UNICEUB foram cientificamente observadas através dos baixos desvios padrão encontrados em todos os grupos tratados, incluindo controle. Ambientes com qualidade geram confiabilidade nos resultados e reduzem o número de animais experimentais necessários para testes in vivo, tão fundamentais para a comprovação de eficácia e inocuidade de produtos injetáveis.

Créditos ao LABOCIEN devem ser concedidos, tanto à gestão quanto equipe de execução e ambiente de trabalho. A reativação do biotério em atividades de pesquisa, e compreensão da urgência no cumprimento de atividades com protocolos ainda em construção, trouxe desafios para ambos lados, mas muito bem conduzidos. O projeto foi viável por essa interação positiva e mútua.

\subsection{Animais experimentais}

O projeto original solicitara 60 fêmeas e 60 machos para amplo estudo de doserespostas de hormônios nunca antes testados em ratos, tendo variáveis até então desconhecidas pelos proponentes. O pertinente questionamento do CEUA-UniCEUB quanto ao número de animais solicitados, levou à proposição que um teste-piloto fosse executado antes de ampliar os testes potenciais, por ser um produto de efeitos desconhecidos. Programado para ser iniciado em 08/2016, um gap de 3 meses foi necessário para ajuste do número total de animais necessários no projeto originalmente aprovado pelo UNICEUB-CNPq (PIC no 004/2016). 
$\mathrm{Na}$ busca de delineamentos confiáveis estatisticamente com número mínimo de animais, a equipe do projeto propôs, para as gonadotrofinas, executar o protocolo da farmacopéia internacional por Steelman e Pohley (1953) denominado "Ovarian weight in HCG-primed rats", que sugere 6-8 fêmeas pré-púberes/grupo. Para as somatrotrofinas foi adotado mesmo número de animais/grupo, em consonância com artigos internacionais (GUIMARÃES et al., 1996; FARRIS, 2007).

Com argumentação e delineamento científico acordado, o Comitê de Ética no Uso de Animais do UniCEUB concedeu autorização para uso de 7 animais por tratamento. O documento para início de execução do projeto (23/11/2016) coincidiu com período de encerramento do semestre letivo, e recessos da equipe laboratorial e professores. Sendo necessária a produção de ninhadas com animais entre 20 e 30 dias de idade, foi acertado o início para Fevereiro de 2017.

Assim, o projeto programou o uso de 35 fêmeas e 28 machos Rattus novergicus (linhagem Wistar heterozigota) pré-púberes para os testes de gonadotrofinas e somatrotrofina, respectivamente. Após o ajuste de casais, gestação e nascimento em número mínimo para atender todos os grupos experimentais, teve início a primeira ação experimental dentro do biotério, em $1^{\circ}$ de Junho.

\subsection{Rotina do biotério no período experimental}

Os jovens ratos pré-púberes foram desmamados com idade mínima de 21 dias. $\mathrm{Na}$ primeira $2^{\mathrm{a}}$ feira disponível após o desmame os animais foram pesados e aleatoriamente distribuídos nos tratamentos. Individualizados em caixas com maravalha, ração e água ad libitum, os tratamentos foram equitativamente distribuídos nas estantes ventiladas.

Toda segunda e quinta-feira no decorrer do experimento a água e ração foram trocadas para fins de pesagem para acompanhamento do consumo e para evitar acúmulo de saliva nas garrafas de água. Nesses dias também houve avaliação da maravalha e, nos casos em que essa se encontrou suja ou molhada, foi realizada a troca.

Durante os procedimentos experimentais, as caixas individuais foram retiradas das estufas por estantes, em grupos de três, e colocadas sobre uma mesa. Os 
animais foram retirados das caixas um por um, pela base da cauda, e foi realizada a contenção deste por um contendor devidamente equipado com EPIs (luva de látex descartável, jaleco e máscara descartável), que consistiu no posicionamento do polegar e do indicador na altura do pescoço do animal e tensão da pele dessa região, impedindo a mobilidade do pescoço, evitando assim possíveis agressões.

Outro voluntário também devidamente equipado com EPIs realizou a aplicação do hormônio no tecido subcutâneo inguinal enquanto o rato estava devidamente contido. No caso das fêmeas tratadas com 0,025 UI, $1 \mathrm{UI}$ e $10 \mathrm{UI}$ de gonadotrofina equina ou $10 \mathrm{UI}$ de eCG, que eram associadas a $4 \mathrm{UI}$ de hCG, foram realizadas duas aplicações diárias, uma no tecido subcutâneo inguinal esquerdo e outra no direito, alternando o que era aplicado de cada lado a fim de observar alguma alteração.

\subsection{Parâmetros de pré-puberdade em Rattus novergicus}

Os referenciais de pré-puberdade nos ratos foi regido por aqueles relatados na literatura internacional, que citam idade entre 21-30 dias de vida e peso corporal entre 40-70g (STEELMAN e POHLEY, 1953; LUNENFELD, 2004; ALAVAREZ et al., 2016).

\subsection{Preparação dos hormônios}

\section{Hormônios hipofisários equinos}

Todos os hormônios hipofisários foram obtidos com matéria-prima de abatedouro registrado e inspecionado de São Gabriel-RS. Depois de congeladas no abatedouro e remetidas a Brasília-DF onde o processamento consistiu na limpeza e higienização das peças, seguida de trituração e coagem, regulações de $\mathrm{pH}$, centrifugação e sucessivas diálises em membrana semi-permeável. Os produtos utilizados no processo de extração asseguram a inocuidade microbiológica do mesmo. Os extratos foram acondicionados em frascos de vidro estéreis para conseguinte liofilização. Os hormônios destinados a todo o período experimental foram provenientes de uma mesma partida de fabricação. 
Todos os hormônios foram diluídos em solução fisiológica estéril, sendo $0,05 \mathrm{ml} /$ dose. As doses, mantidas em freezer $-20^{\circ} \mathrm{C}$ eram descongeladas pelo calor da palma das mãos no momento de uso. Qualquer excedente diário contido nas seringas descongeladas será descartado, não sendo permitido o re-congelamento, conforme recomendado para qualquer solução hormonal proteica diluída. Os animais do Grupo Controle receberão a mesma dose diária de solução fisiológica, que servirá como placebo.

\section{Gonadotrofina comercial}

A gonadotrofina comercial utilizada no experimento $\left(\right.$ Novormon $\left.^{\circledR}\right)$ foi diluída em água para injeção conforme indicado pelo fabricante. A dose foi ajustada para volume final de $0,05 \mathrm{ml}$, assim como os demais grupos.

\subsection{Protocolos de tratamento hormonal}

\section{Gonadotrofinas}

Um total de 35 ratas pré-púberes com peso vivo inicial médio de $42,59 \mathrm{~g}$ foram distribuídas em 5 tratamentos: Placebo (solução fisiológica), 0,025UI, $1 \mathrm{UI}$ ou $10 \mathrm{UI}$ de gonadotrofina hipofisária equina, ou 10UI de eCG (Novormon®). Os tratamentos consistiram em uma aplicação diária via subcutânea inguinal entre 18:00 h e 19:00 h, por 3 dias consecutivos, associados com uma dose 4Ul/dia de hCG para potencialização dos efeitos $\mathrm{FSH}$, conforme protocolo da farmacopéia internacional. As fêmeas foram mantidas em gaiolas individuais, estantes ventiladas, com ciclo de 12 horas escuro e 12 horas claro, água e ração ad libitum. Dezoito horas após a última aplicação os animais foram eutanasiados.

\section{Somatotrofinas}

A somatotrofina foi testada em 28 machos pré-púberes com peso corporal inicial médio de 50,7g nos tratamentos Placebo, 0,025UI, $1 \mathrm{UI}$ ou $10 \mathrm{Ul}$ de somatotrofina hipofisária equina por dose, via subcutânea, 3 dias/semana ( $\left(2^{\mathrm{a}}, 4^{\mathrm{a}}\right.$ e $\left.6^{\mathrm{a}}\right)$, às 11:30 da manhã, durante 30 dias. Nenhum produto equivalente é comercializado no Brasil, tendo sido inviável estabelecer grupo padrão nos testes de somatotrofina. 
Os animais foram mantidos em gaiolas individuais em estantes ventiladas, com ciclo de 8 horas escuro e 8 horas claro, água e ração ad libitum. Ao final dos 30 dias experimentais os animais foram eutanasiados.

\subsection{Dissecação e avaliação dos animais}

Ao final do experimento a eutanásia dos animais foi conduzida em grupos de até oito indivíduos por seção, evitando alteração post-mortem do material biológico. De acordo com as boas práticas de bem-estar animal, os animais foram removidos do biotério com atitudes para minimizar o estresse de modificação de ambiente.

Cuidadosamente conduzidos em carro inoxidável de transporte coberto com lençol, foram individualmente colocados em câmara de inalação. O balão de oxigênio foi ligado seguido pela abertura do fluxômetro do cilindro de gás carbônico a $30 \mathrm{lb}$. Aproximadamente 2,5 a 3 minutos de tempo foram observados entre a perda de consciência, aprofundamento do plano anestésico até o óbito, confirmado por Médico Veterinário, conforme legislação de biosseguraça.

Em laboratório previamente preparado no $L A B O C I E N$, foi verificado peso corporal $(\mathrm{g})$ e comprimento $(\mathrm{cm})$, e executada inspeção externa dos animais eutanasiados. A necropsia era iniciada com a inspeção da cavidade abdominal e remoção do trato reprodutivo, sendo imediatamente enviado para os processamentos seguintes.

Em seguida, tinha início coleta de órgãos fundamentais com a remoção do conjunto fígado-baço, seguida pelo conjunto rins-adrenais. Na cavidade toráxica era removido o conjunto pulmão-coração. Nesse momento todas as peças eram fixadas para enviado `a UnB. Com carcaça livre das peças principais, o membro posterior esquerdo foi removido e congelado para análise do desenvolvimento da tíbia.

\subsection{Avaliação histológica}

Imediatamente à necropsia os órgãos avaliados eram fotografados. Após pesagem, as peças foram integralmente fixadas em formaldeido $10 \%$, a não ser o fígado, que teve apenas biópsia amostrada. As amostras eram enviadas para 
processamento pelo Laboratório de Patologia Animal da Universidade de Brasília (UnB) para processamento e avaliação histológica das estruturas.

$\mathrm{Na}$ UnB as peças fixadas foram preparadas em lâminas e coradas em Hematoxilina-Eosina. Nos ovários das fêmeas foram identificados e contados folículos antrais, folículos em crescimento, corpo hemorrágico e corpo lúteo. As amostras dos machos seguem em processamento.

\subsection{Análise de dados}

Para avaliação da resposta às gonadotrofinas foram calculadas as médias de peso corporal inicial, peso corporal final (post-mortem imediato), consumo de água, consumo de ração e peso ovariano. Para avaliação da resposta à somatotrofina foram calculadas as médias de peso corporal inicial, peso corporal final (postmortem imediato), comprimento, e pesos das vísceras fígado, coração, baço e rins. Todos os tratamentos tiveram delineamento inteiramente casualizado com 7 repetições, sendo as médias resultantes comparadas pelo teste de Tukey ao nível de $1 \%$ de probabilidade.

\section{Resultados e discussão}

\section{Quanto ao ciclo biológico dos ratos $\angle A B O C I E N$}

A análise histológica do primeiro lote de ovários $(n=14)$ revelou puberdade acima de $60 \mathrm{~g}$, peri-puberdade entre $60-50 \mathrm{~g}$, e pré-púberdade abaixo de $50 \mathrm{~g}$. As constantes pesagens e acompanhamento comportamental ajudaram a entender o ciclo biológico dos animais do micro-ambiente proporcionado pelo LABOCIEN para atingir as metas do projeto.

Assim, foi descoberto que, nos animais daquele período experimental, a prépúberdade de fêmeas e machos seria atendida com peso corporal inicial entre 3249g. Um eficiente planejamento de ninhadas e sincronia de partos permitiu rápido delineamento e execução do experimento formal, finalizando o último lote experimental em 28 de Junho de 2016. 


\section{Quanto ao tratamento com gonadotrofinas}

Nenhuma reação local ou alteração foi observada na região de aplicação, ou mudança de comportamento nas fêmeas. Foi notado, entretanto, que reagiam muito à aplicação do hCG, ficando inquietas e ruidosas a aplicação.

Tabela 1 - Avaliação de dose-resposta ovariana para $\mathrm{FSH}^{*}$ em fêmeas Rattus novergicus (Linhagem Wistar heterozigotas) pré-púberes induzidas com gonadotrofina hipofisária equina em três diferentes concentrações e gonadotrofina coriônica equina (eCG) de uso comercial (10Ul/dia). .*

\begin{tabular}{|c|c|c|c|c|c|c|c|}
\hline \multirow{2}{*}{ Tratamento } & \multirow{2}{*}{$\mathrm{n}$} & \multicolumn{2}{|c|}{ Peso corporal (g) } & \multicolumn{2}{|c|}{ Ganho de Peso } & \multicolumn{2}{|c|}{ Peso ovariano } \\
\hline & & Inicial & Final & $\begin{array}{l}\text { Absoluto } \\
(\mathrm{g})\end{array}$ & $\begin{array}{c}\text { Relativo } \\
(\%)\end{array}$ & $\begin{array}{c}\text { Absoluto } \\
(\mathrm{g})\end{array}$ & $\begin{array}{c}\text { Relativo } \\
(\%)\end{array}$ \\
\hline Placebo & 7 & $43,09^{a}$ & $55,33^{a}$ & $12,23^{a}$ & $30,72^{a}$ & $0,27^{a}$ & $0,46^{\underline{a}}$ \\
\hline 0,025 UI & 7 & $42,09^{a}$ & $53,97^{\mathrm{a}}$ & $11,87^{a}$ & $28,04^{a}$ & $0,37^{a, b}$ & $0,63^{b}$ \\
\hline $1 \mathrm{UI}$ & 7 & $44,46^{a}$ & $56,62^{a}$ & $12,15^{\mathrm{a}}$ & $29,29^{a}$ & $0,36^{a, b}$ & $0,63^{b}$ \\
\hline $10 \mathrm{UI}$ & 7 & $40,79^{a}$ & $53,29^{a}$ & $12,49^{a}$ & $30,42^{\mathrm{a}}$ & $0,51^{b}$ & $1,01^{\mathrm{c}}$ \\
\hline eCG & 7 & $42,55^{a}$ & $53,47^{a}$ & $10,92^{\mathrm{a}}$ & $26,75^{a}$ & $0,42^{a, b}$ & $0,83^{b, c}$ \\
\hline
\end{tabular}

* 3 doses diárias consecutivas às 18 horas, via subcutânea, todas associadas 4 UI de hCG, com finalização do experimento 18 horas após última aplicação. Regime de 12 horas/luz/dia.

** Novormon® (Zoettis-Argentina)

O menor peso ovariano $(0,46 \mathrm{~g})$ e a ausência de estruturas de ovulação (corpo hemorrágico ou lúteo) no grupo Placebo conferiu segurança ao experimento por confirmar que a média de peso corporal inicial de 42,59g foi pré-púbere.

A média de peso ovariano do grupo $10 \mathrm{Ul}$ gonadotrofina hipofisária equina $(1,01 \mathrm{~g})$ foi similar $(p<0,01)$ ao grupo padrão, com 10Ul de eCG $(0,83 g)$. De acordo com o protocolo sugerido por Steelman e Pohley (1953), o resultado comprovou a atividade de $\mathrm{FSH}$ da gonadotrofina hipofisária equina em ratos segundo as normas internacionais.

As imagens macroscópicas (Figura 1) também mostraram que há diferenças no padrão de irrigação sanguínea, sendo o Placebo o menos expressivo nessa observação. Futuros estudos devem incluir essa análise. 
Figura 1 - Imagem fotográfica do aparelho reprodutor de fêmeas Rattus novergicus grupo Placebo (A), 0,025UI (B), 1UI (C) ou 10UI (D) de gonadotrofina equina, e 10UI de eCG (E).
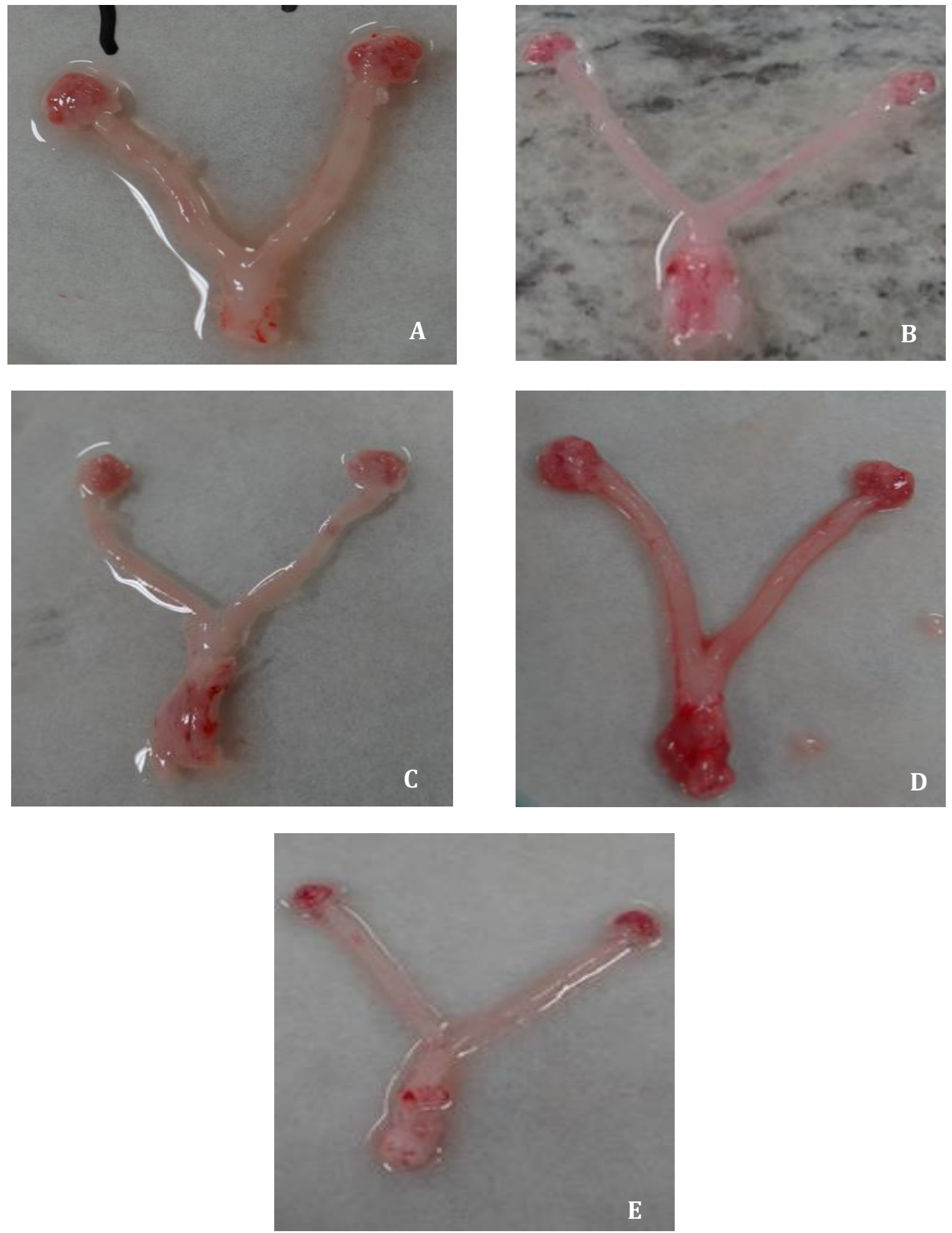

Fonte: Arquivo fotográfico Projeto 004/2016 - disponível 
Com a parceria com a UnB foi possível analisar parte dos tecidos ovarianos a tempo das publicações. Os demais tecidos continuam sendo processados e comporão publicação completa no futuro. As avaliações histológicas dos ovários amostrados estão sumarizadas na Tabela 2.

Tabela 2 - Avaliação histológica de ovários de fêmeas Rattus novergicus (Linhagem Wistar heterozigotas) pré-púberes induzidas com gonadotrofina hipofisária equina em três diferentes concentrações e gonadotrofina coriônica equina (eCG) de uso comercial (10Ul/dia).*

\begin{tabular}{|c|c|c|c|c|c|c|c|}
\hline \multirow{3}{*}{ Tratamento` } & \multirow{3}{*}{$\mathrm{N}$} & \multicolumn{6}{|c|}{ Estruturas ovarianas ${ }^{* *}$} \\
\hline & & \multirow{2}{*}{$\begin{array}{l}\text { Folículos } \\
\text { Antrais }\end{array}$} & \multirow{2}{*}{$\begin{array}{l}\text { Folículos } \\
\text { crescimento }\end{array}$} & \multicolumn{2}{|c|}{ Corpo hemorrágico } & \multicolumn{2}{|c|}{ Corpo lúteo } \\
\hline & & & & Total & Média & Total & Média \\
\hline Placebo & 3 & Numerosos & Numerosos & 0 & 0 & 0 & 0 \\
\hline 0,025 UI & 3 & Numerosos & Numerosos & 0 & 0 & 9 & 3 \\
\hline $1 \mathrm{UI}$ & 3 & Numerosos & Numerosos & 0 & 0 & 5 & 1,7 \\
\hline $10 \mathrm{UI}$ & 2 & Numerosos & Numerosos & 1 & 0,5 & 10 & 5 \\
\hline eCG & 2 & Numerosos & Numerosos & 0 & 0 & 11 & 5,5 \\
\hline
\end{tabular}

Todos os demais grupos de gonadotrofina hipofisária equina também foram capazes de induzir ovulação, confirmada pela presença de corpo lúteo. Isso indica atividade de $\mathrm{FSH}$ em todas as concentrações propostas.

Foi interessante observar que o grupo $0,025 \mathrm{UI}$ promoveu ovulações, bem como 0 grupo $1 \mathrm{UI}$, estabelecendo parâmetro com equino. A dose $0,025 \mathrm{Ul}$ foi proposta de acordo com a relação atual de dose em equino de $125 \mathrm{Ul} / 500 \mathrm{~kg}$ peso corporal. Tal entendimento é muito valioso para ajuste de bioequivalência hormonal.

Um dos problemas relatados no uso do eCG, pelas características das proteínas presentes e farmacodinâmica do produto hormonal, é manter concentração plasmática por até 3 dias (LUNENFELD, 2004; ALVAREZ et al., 2016). Com as 3 aplicações consecutivas, conforme protocolo internacional, é possível ter ocorrido efeito somatório nos grupos de dose mais elevada. 
Conhecer um hormônio protéico a ponto de poder ajustar finamente as doses terapêuticas é um benefício, pois aumenta a precisão e pontualidade dos efeitos desejados. O tema indução de ovulação é tão atual que foi publicado um estudo conjunto da Agência Paulista de Tecnologia dos Agronegócios (APTA) e o Instituto de Pesquisas Nucleares e Energéticas (IPEN-CNEN) sobre os perfis proteicos e atividade biológica do eCG em 4 produtos comerciais importados pelo Brasil e produto padrão internacional da Sigma ${ }^{\circledR}$ (ALVAREZ et al., 2016). O artigo comprovou ser o Novormon ${ }^{\circledR}$, usado como controle-padrão do presente projeto, aquele de qualidade biológica de proteína mais compatível com o padrão internacional.

Por outro lado, os parâmetros biológicos relatados por Alvarez e seus colaboradores utilizando fêmeas Rattus novergicus produzidas pelo CEMIBUNICAMP, mesma origem genética dos animais do LABOCIEN, foram muito contrastantes. Os autores relataram início dos tratamentos com fêmeas pré-púberes Wistar de peso corporal inicial médio de $65,5 \mathrm{~g}$ aos 21 dias de idade. Assim, os animais do IPEN-CNEN estariam desmamando 3 vezes mais pesados do que a média encontrada no LABOCIEN.

Diferenças como esta dificultam a execução de delineamentos precisos na reprodução. Por seus ganhos em informação para o biotério do UNICEUB, a equipe entendeu que o trajeto de investigação resultante desse projeto, mesmo utilizando número maior de animais, tenha sido importante e necessário para futuros trabalhos de todas as áreas. Relatórios e dados estão todos disponíveis para análise do LABOCIEN e CEUA-UNICEUB (Livro-Ata PIC 004/2016).

\section{Quanto à somatotrofina}

Nos primeiros lotes experimentais a contenção foi realizada com a utilização de um pano, que era colocado por cima da cabeça e pescoço do animal, o que impedia a visualização do contendor. Após 2 semanas, o pano foi enviado para limpeza sem retornar, e a contenção passou a ser realizada sem o mesmo. 
Coincidentemente, casos de coceira crônica no pescoço apareceram em todos os grupos, inclusive placebo, mas sem prejuízo para a saúde dos animais. Isso levou a equipe a associar a contenção diretamente com a luva como um possível efeito irritante no local. Após alguns dias, houve redução dessa reação. Amostras de tecidos foram fixadas para análise histológica, para fins de investigação.

Apesar do projeto não ter criado mecanismos específicos de avaliação de comportamento, a percepção foi natural. Assim, após 15 dias de aplicações a equipe observou mudança de comportamento nos machos do tratamento de $10 \mathrm{UI}$, notando maior agressividade e agitação durante o manejo e contenção, se contorcendo ao serem contidos, emitindo muitos ruídos e por vezes tentando morder o contendor ou o aplicador.

Os resultados do uso de somatrotrofina hipofisária equina nos machos estão sumarizados na Tabela 3.

Tabela 3 - Medidas corporais e de órgãos fundamentais (g) de machos Rattus novergicus (Wistar heterozigotos) pré-púberes tratados por 30 dias $^{*}$ com somatotrofina hipofisária equina em três diferentes concentrações.

\begin{tabular}{|c|c|c|c|c|c|c|c|c|}
\hline \multirow{2}{*}{ Tratamento } & \multicolumn{3}{|c|}{ Peso corporal (g) } & \multicolumn{4}{|c|}{ Peso órgãos } & \multirow{2}{*}{$\begin{array}{c}\text { Comprimento } \\
\text { Total }(\mathrm{cm})\end{array}$} \\
\hline & Inicial & Final & $\begin{array}{c}\text { Ganho } \\
\text { diário }\end{array}$ & Fígado & Coração & Baço & Rins & \\
\hline Placebo & $44,9^{\mathrm{a}}$ & $211,5^{\mathrm{a}}$ & $162,01^{a}$ & $12,38^{\underline{a}}$ & $0,93^{\underline{a}}$ & $0,69^{a}$ & $2,4^{\underline{a}}$ & $35,21^{a}$ \\
\hline 0,025 UI & $52,54^{a}$ & $210,58^{a}$ & $158,05^{a}$ & $11,96^{\underline{a}}$ & $0,92^{\mathrm{a}}$ & $0,71^{a}$ & $2,23^{a}$ & $36,07^{a}$ \\
\hline $1 \mathrm{UI}$ & $55,82^{\mathrm{a}}$ & $219,37^{a}$ & $163,54^{\underline{a}}$ & $12,63^{\text {a }}$ & $0,97^{a}$ & $0,7^{a}$ & $2,31^{a}$ & $36,04^{\underline{a}}$ \\
\hline $10 \mathrm{UI}$ & $49,38^{\underline{a}}$ & $214,43^{a}$ & $165,11^{a}$ & $12,64^{\underline{a}}$ & $1,01^{\underline{a}}$ & $0,72^{\underline{a}}$ & $2,41^{\underline{a}}$ & $35,68^{\underline{a}}$ \\
\hline
\end{tabular}

Não houve diferença entre as médias de peso corporal final (50,7g), comprimento $(35,8 \mathrm{~cm})$, ou peso médio relativo dos órgãos fundamentais, bem como seu aspecto. Todos os órgãos avaliados em todos os tratamentos foram fixados em formaldeído 10\% para análise microscópica. 
As imagens macroscópicas do aparelho reprodutor dos machos (Figura 2) revelaram aparente diferença no padrão de irrigação sanguínea, com maior ramificação e espessamento aparente nos vasos dos testículos, epidídimo, ducto deferente, vesícula seminal e plexo pampiniforme. Houve também aparente incremento de gordura justaposta aos órgãos fundamentais e plexo pampiniforme. A análise dos cortes histológicos pela UnB será necessária para conclusões precisas.

Figura 2 - Imagem fotográfica do aparelho reprodutor de machos Rattus novergicus tratados com Placebo (A), 0,025UI (B), 1UI (C) ou 10Ul (D) de somatotrofina hipofisária equina.
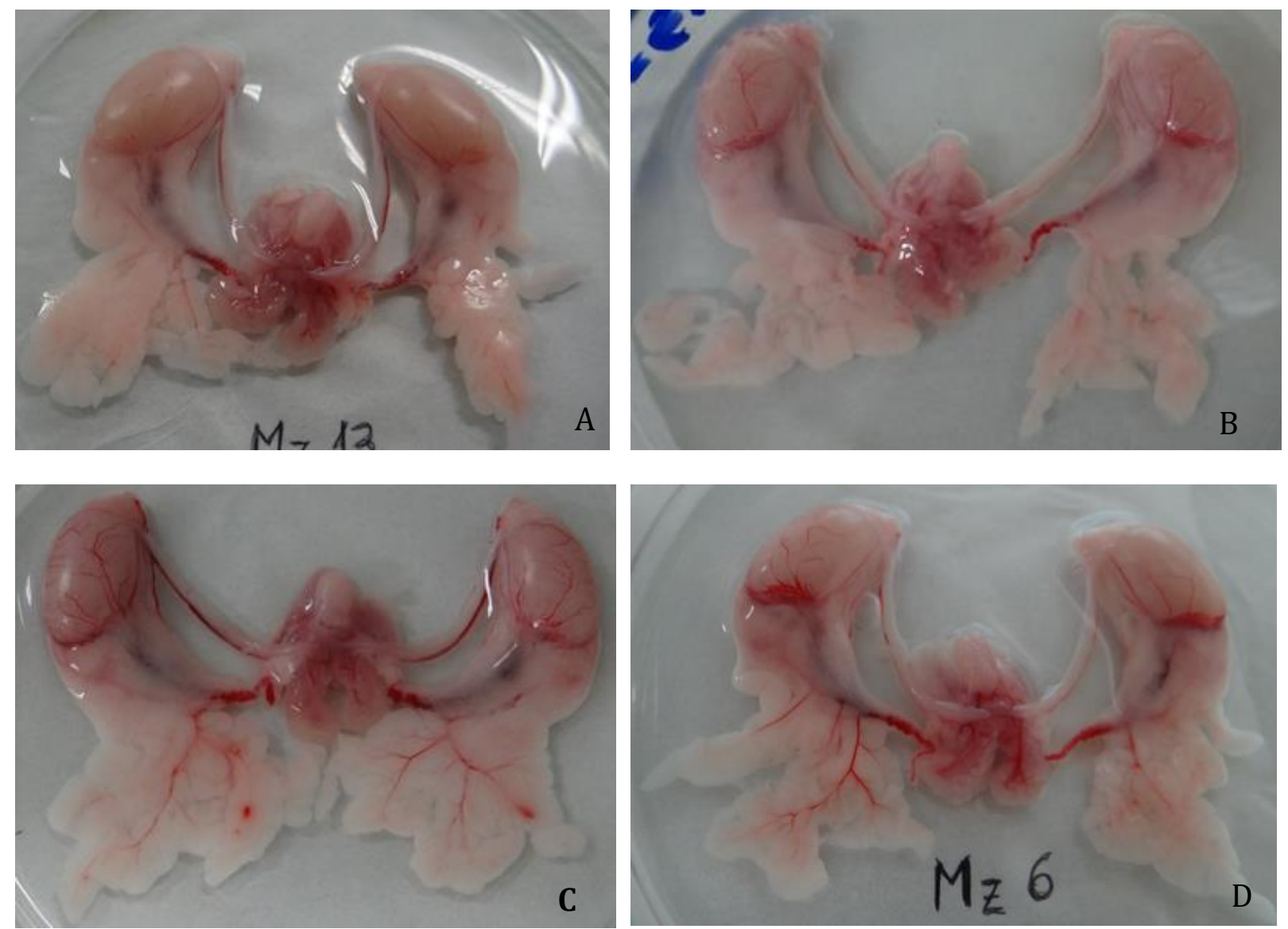
Assim como nas gonadotrofinas, profundo interesse tem sido demonstrado pelo estudo das somatotrofinas, e de forma muito relevante seus efeitos na reprodução. Dos peixes aos humanos, a somatrotrofina, ou hormônio do crescimento, ou GH, atua e regula direta e intensamente o eixo-hipotalâmicohipofisário-gonadal das gonadotrofinas, e atua da mesma forma no estímulo da mitose esteroidogênese celular no aparelho reprodutor de machos e fêmeas (COCHRAN et al., 1999; HULL e HARVEY, 2000, 2001, 2014).

Da estimulação de angiogênese à multiplicação de células germinativas e qualidade celular, diversos trabalhos citam os parâmetros de modificação do $\mathrm{GH}$ sobre a irrigação, assim como encontrado nos grupos tratados no presente projeto. Apesar de estarem disponíveis para cortes na UnB, será necessário estudar a melhor metodologia para analisar angiogênese e alterações morfogênicas profundas das células.

Outra observação interessante surgiu durante a necropsia. Apesar de não ter ocorrido desenvolvimento corporal distinto entre os grupos, sutilezas passaram a ser observadas à medida que a equipe ficava mais habilidosa. Duas foram marcantes no grupo de 10Ul. A primeira um maior sangramento à necropsia. O segundo sobre a distribuição da gordura corporal.

Nenhum grupo apresentou gordura subcutânea ou superficial na musculatura. Por outro lado, foi notável o incremento de gordura abdominal localizada rente às laterais da coluna vertebral, especialmente peri-renal, e junto ao aparelho reprodutor. De coloração brancacenta e extremamente friável, tinha aspecto de recente formação.

Tal informação deve ser estudada e encarada como sintoma precioso da atividade somatogênica. Isso porque o GH é um hormônio catabólico-anabólico, nessa ordem no tempo. Suas atividades a curto prazo envolvem ativação metabólica geral, interferindo inclusive na ativação do TSH e GnRH hipotalâmicos nessa intenção. Com isso, promove constante e gradual incremento da disponibilidade de glicose circulante, que será direcionada especialmente para aqueles órgãos mais metabolicamente ativos. Na busca de recursos nutricionais que contribuam com a riqueza plasmática de glicose, a lipidólise em prol de gliconeogênese requer boa 
parte dos recursos imobilizados na forma de gordura superficial, ou de cobertura (HULL e HARVEY.

Essa atividade promove uma cascata de modificações orgânicas em um quadro fisiológico denominado de diabetogênico. O estado diabetogênico tem sido muitíssimo explorado pela endocrinologia, pois é encontrado em um grande número de distúrbios endócrinos como a diabetes, hipertiroidismo, terapias com corticoide e outras.

Dentro do tema, surgiu nos últimos anos interesse por um conjunto de problemas associados com efeitos diabetogênicos, a síndrome metabólica. Com uma complexidade multifacetada, o fator patognomônico é a gordural visceral, mais especialmente aquela justaposta ao abdômen dorsal, próximo aos rins (FILHO et al., 2006) Descritivamente a mesma encontrada nos grupos de somatotrofina equina de dose alta, principalmente.

O experimento de $\mathrm{GH}$ desse projeto foi delineado para cumprir a mais suave posologia possível, já que seriam 30 dias em tratamento. Terapeuticamente, esse corresponde ao um período catabólico de intenso ajuste do metabolismo. Nesse sentido, o experimento englobou esse estado fisiológico, já que a atividade anabólica conjunta é observada com tempo mínimo de 60 dias.

Em intensa atividade catabólica, é esperado que o efeito diabetogênico estaria presente, e a gordura abdominal encontrada passaria a ser uma evidência importante para futuros estudos. As investigações desse campo querem coleta de materiais in vivo para acompanhamento plasmático de distintas substâncias.

Para fins de efeitos anabólicos novos delineamentos deverao ser propostos, permitindo a avaliação a longo prazo. A ausência de reações indesejáveis nos grupos tratados foi um achado muito importante. 


\section{Considerações finais}

As orientações de cautela propostos pelo CEUA-UNICEUB quanto ao número de animais foi fundamental para definição de um protocolo mínimo e eficiente. Originalmente solicitando 120 animais, contra os 63 realmente necessários, nenhum animal excedente deixou de contribuir cientificamente e em amplo benefício.

Saber da importância em conhecer o ciclo biológico das populações no momento de um experimento no biotério do LABOCIEN, já que isto pode mudar, ajuda imensamente na condução de delineamentos de pesquisa mais assertivos e uso minimizado de animais. As informações e habilidades conjuntas das equipes incrementadas durante as atividades reforçam a confiança nos resultados obtidos nos presentes experimentos.

O sucesso na atividade biológica das gonadotrofinas hipofisárias equina foi ganho inestimável do projeto. Após 13 anos de estudos em equinos e ensaios e outras espécies, a confirmação de sua atividade em Rattus novergicus nesse experimento torna mais clara a capacidade de atividade heteróloga do hormônio, como esperado para o equino como fonte da matéria prima.

A capacitação dos estudantes e a dedicação nas atividades, ocorridas durante 0 período de provas semestrais e férias, mostrou a importância da iniciação científica. Com equipe flutuante de até 10 estudantes voluntários, o projeto foi precisamente conduzido por 3. Por fim, 5 estudantes estão hoje interessados nos projetos científicos, e devem progredir para estudos em outras espécies. Uma estudante foi selecionada para dar continuidade no entendimento do biotério, com animais sendo renovados, bem como a extensão dos conhecimentos para outros grupos de pesquisa e projetos.

O envolvimento dos estudantes com o projeto, o ambiente do biotério e a observação animal foram fundamentais para entender efeitos dos hormônios, efeito do animal, efeito da altura na prateleira (que interferiu no desenvolvimento no $\mathrm{GH}$ ), agressividade do grupo $10 \mathrm{UI}$ de somatotrofina, reações de vocalização exacerbada à aplicação de hCG. Não utilizar o pano de contenção foi outro ganho, de aprendizado sobre a importância de cada detalhe para os quais são instruídos. A 
hipótese de alergia à manipulação com luva foi levantada pelos estudantes. A razão para não utilizar era superável, mas dúvidas sobre a origem das coceiras, e chamando atenção à consciência científica. A ausência de outros sinais de reação adversa foram pontos muito positivos do trabalho.

$\mathrm{Na}$ branda posologia executada para a somatotrofina equina apenas sinais tênues foram observados, e deverao ser aprofundados com a analise de cortes histológicos, bem como delineamentos mais direcionados para período mais longo. A avaliação morfometrica da tíbia esquerda esta sendo executada, e devera compor novas analises, sendo incluída em publicação completa de artigo.

Enfim, o projeto atingiu seus objetivos quanto `a motivação e capacitação de estudantes, confirmação da atividade das gonadotrofinas e indicações importantes da atividade da somatrotrofina equina. Novas proposições, mais precisas e objetivas serão possíveis após o rico trabalho desenvolvido.

\section{Referências bibliográficas}

Aleixo, J.A.G; Deschamps, J.C.; Bordignon, V. et al. Gonadotrofina corionica equina: purificação, caracterização e resposta ovariana em ovinos e suínos. Ciência Rural, v.25, n.1, p.11-114, 1995.

ASRM - American Society for Reproductive Medicine. Gonadotropin preparations: past, present and future perspectives. Fertil. Steril., n. 90, p. 13-12, 2008.

Alvarez, R.H; Natal, F.L.N.; Ribela, M.T.C.P.; Almeida, B.E.; Oliveira, J.E.; Bartolini, $P$. Physical-chemical and biological characterization of different preparations of equine chorionic gonadotropin. J Vet Sci, n.17, v.4, p.459-465, 2016.

Ayyar, V.S. History of growth hormone therapy. Indian J. Endocrinol. Metab., n.15 (Suppl3), p.162-165, 2011.

Baruselli, P.S.; Jacomini, J.O.; Sales, J.N.S. et al. Importância do emprego da eCG em protocolos de sincronização para IA, TE e SOV em tempo fixo. In: Anais $3^{\circ}$ SIMPÓSIO INTERNACIONAL DE REPRODUÇÃO ANIMAL APLICADA Biotecnologia da reprodução. p.146-167. 2008.

Casanueva, F.F. Physiology of growth hormone secretion and action. Endocrinol. Metab. Clin. North Am., v.21, p. 483-517, 1992.

Cochran, RA, Leonardi-Cattolica, AA, Sullivan, MR, Kincaid LA, Leise BS, Thompson $\mathrm{DL} \mathrm{Jr}$, Godke RA. The effects of equine somatotropin (eST) on follicular development and circulating plasma hormone profiles in cyclic mares treated during different stages of the estrous cycle. Domest Anim Endocrinol., v.16, p.57-67, 1999. 
Crowe, S.J.; Cushing, H.; Homans, J. Experimental hypophysectomy. Bull. Johns Hopkins Hosp., n. 21, p. 127-167, 1910.

Davidson, M.B. Effect of growth hormone on carbohydrate and lipid metabolism. Endocr. Rev., n.8, p. 115-131, 1987.

De Botton, D; Janett, F; Burger, D et al. Influence of long-term treatment with equine somatotropin (EquiGen) on gonadal function in stallions with poor semen quality. Schweizer Archiv für Tierheilkunde, v.150, n.4, p.157-65, 2008.

FAO-WHO. Residue evaluation of certain veterinary drugs. In: $78^{\text {th }}$ Meeting of Joint FAO/WHO Expert Committee on Food Aditives, Geneva, 5-14 de novembro. 2013.

Faria, D.R.; Gradela A. Hormonioterapia aplicada à ginecologia equina. Rev. Bras. Reprod. Anim., v.34, n.2, p.114-122, 2010

Farris, G.M.; Miller, G. K.; Wollenberg G. K. et al. Recombinant Rat and Mouse Growth Hormones: Risk Assessment of Carcinogenic Potential in 2-Year Bioassays in Rats and Mice. Toxicological Sciences, v.97, n.2, p.548-561, 2007.

Filho, F.F.R.; Mariosa, L.S.; Ferreira, S.R.G.; Zanella, M.T. Gordura visceral e síndrome metabólica: mais que uma simples associação. Arq Bras Endocrinol Metab, v. 50, p.230-238, 2006.

HULL, K. L.; HARVEY, S.. Growth hormone: a reproductive endocrine-paracrine regulator. Journals of Reproduction and Fertility, Canadá v.5, n. 3, p.175-182, 2000.

HULL, K. L.; HARVEY, S.. Growth hormone: roles in female reproduction. Endocrinology, v. 168, n.1, p.1-23, 2001.

HULL, K. L.; HARVEY, S.. Growth Hormone and Reproduction: A Review of Endocrine and Autocrine/Paracrine Interactions.International Journal of Endocrinology, V. 2014, Article ID 234014, p.1-25, 2014.

Itho, M.F. Uso de baixas doses de extrato de pituitária eqüina e hormônio de crescimento (somatotrofina) na ndução do estro em éguas em anestro. Dissertação. Universidade Federal do Norte Fluminense. 48p. 2010.

Lunenfeld, Bruno. Historical perspectives in gonadotrophin therapy. Human Reproduction Update, v.10, n.6, p. 453-467, 2004.

Nogueira, M.B.R. Uso de diluição seriada de sêmen criopreservado na inseminação artificial em tempo fixo em éguas Mangalarga Marchador. Tese. Universidade Federal de Lavras. 79p. 2011.

Palmer E. Induction of ovulation. In: McKinnon AO, Voss JL. Equine reproduction. Philadelphia: Lea \& Febiger, 1993. p.344-347. 
Westwood,M.; Maqsood, A.R.; Solomon, M. et al. The effect of different patterns of growth hormone administration on the IGF axis and somatic and skeletal growth of the dwarf rat. Am J Physiol Endocrinol Metab., n. 298, v.3, p. 467-476, 2010.

Zabel M.D.; Reid, C. A brief history of prions. FEMS Pathogens and Disease, n.73, p.1-8, 2015. 